\title{
In Vivo Two-Photon Imaging of Neurons and Glia in the Mouse Spinal Cord
}

\author{
Heinz Steffens, Fabien Nadrigny, and Frank Kirchhoff
}

Two-photon imaging of the nervous system is now used extensively for visualizing brain dynamics and signal activities. To date, scientists have focused on the analysis either of gray matter forebrain structures, such as the cortex and cerebellum, or they have investigated muscle innervation of peripheral nerves. The spinal cord is an ideal structure to use for imaging central nervous system white matter. The dorsal columns formed by myelinated sensory axons are located directly at the surface of the spinal cord underneath the pia mater. This protocol describes a method for imaging neuronal fibers and neighboring glial cells in transgenic mice using cell type-specific fluorescent protein expression and two-photon laser-scanning microscopy (2pLSM). Depending on how the mice are prepared, single imaging can be performed, or the spinal cord can be imaged repetitively over multiple days, with time for the mouse to recover between imaging sessions.

It is essential that you consult the appropriate Material Safety Data Sheets and your institution's Environmental Health and Safety Office for proper handling of equipment and hazardous materials used in this protocol.

RECIPE: Please see the end of this article for recipes indicated by $<R>$. Additional recipes can be found online at http://cshprotocols.cshlp.org/site/recipes.

Reagents

ACSF for 2pLSM $<\mathrm{R}>$

Agar, $2 \%$ in ACSF for 2pLSM

Mice, prepared surgically in one of two ways: Preparation of the Mouse Spinal Column for Single Imaging Using Two-Photon Laser Scanning Microscopy (Steffens et al. 2012a) or Preparation of the Mouse Spinal Column for Repetitive Imaging Using Two-Photon Laser Scanning Microscopy (Steffens et al. 2012b)

Texas Red-dextran (70-kDa, 1.25\% [w/v], Invitrogen)

Equipment

Anesthesia equipment

Cotton swabs

Dichroic mirror, 520-nm (Semrock)

Filter, long-pass, 560-nm (Carl Zeiss)

Adapted from Imaging in Neuroscience (ed. Helmchen and Konnerth). CSHL Press, Cold Spring Harbor, NY, USA, 2011.

(C) 2012 Cold Spring Harbor Laboratory Press

Cite this article as Cold Spring Harb Protoc; 2012; doi:10.1101/pdb.prot072264 
Downloaded from http://cshprotocols.cshlp.org/ on April 25, 2023 - Published by

In Vivo Two-Photon Imaging of the Spinal Cord

Filters, emission, (500 \pm 12-nm, $542 \pm$ 27-nm, 460/80BP [Semrock]; HQ575 [AHF Analysentechnik]) Imaging setup

Any commercial or custom-made two-photon laser-scanning microscope can be used. It should be capable of low-magnification epifluorescence and bright field imaging in a separate channel that is used for overviews (e.g., Zeiss HBO 103 and a 5×, 0.15-numerical aperture [NA] objective). A charge-coupled device (CCD) camera is required for recording these images.

For 2pLSM, a long-distance $20 \times$ objective with high NA is essential (e.g., Zeiss W Plan-Apochromat 20×, 1.0 NA DIC). For excitation, use a femtosecond-pulsed titanium-sapphire laser (e.g., Chameleon Ultra II, Coherent). To optimize the spatial resolution and the detection efficiency, fill $80 \%$ of the 17-mm-wide back aperture of the $20 \times$ objective. In addition, use two lenses to focus the fluorescence signal into the photomultiplier tubes. For deep tissue penetration, glass dispersion compensation is recommended (either as a separate module or integrated into the system (e.g., Coherent Vision II). Control the laser intensity with a Pockels cell (Conoptics). Scanimage version 3.5 is the image control software that we use (Pologruto et al. 2003).

Power supply for the heat pad (12-V, 1-A)

Rectal temperature sensor and display

Scalpel

Scissors

Support for the mouse, heated by a flat heat pad, with rail bars to fix two vertebral clamps for the backbone and the volatile anesthesia equipment

Thread or suture material

Vertebral clamp holders (two) for the backbone (Narishige or custom-made)

\section{METHOD}

\section{Mounting of the Vertebral Column}

For nearly motionless imaging, the vertebral column has to be mounted to two vertebral clamps (Fig. 1A,B).

1. Fix the lateral joint processes of the vertebrae next to the prepared region rostrally and caudally.
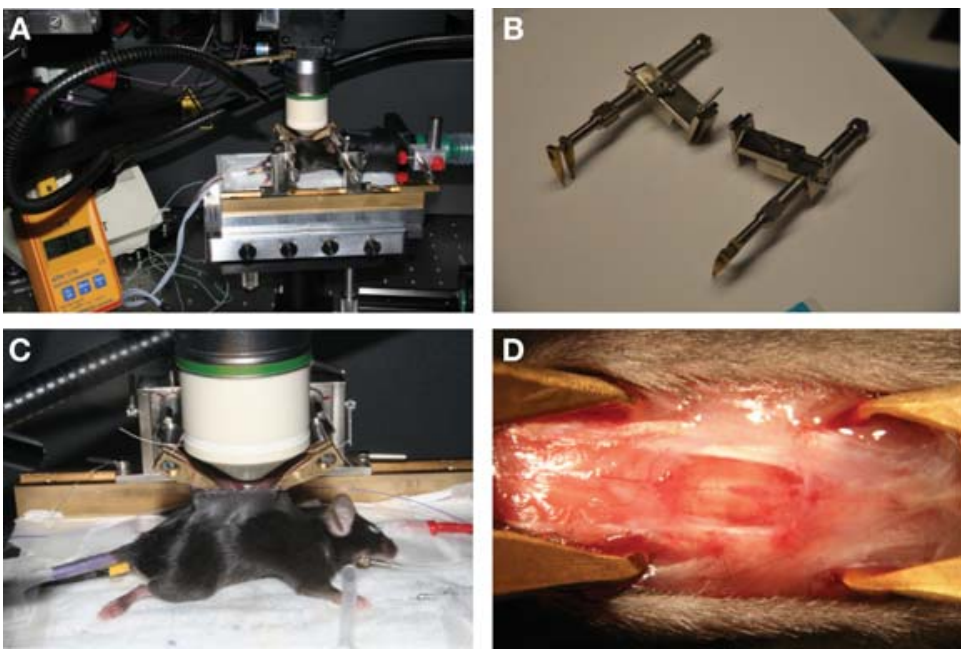

FIGURE 1. Preparation of mice for spinal cord imaging. (A) Mouse receives a volatile anesthetic, a rectal probe (see also $C)$ monitors temperature, and imaging is performed with a high numerical aperture, $20 \times$ objective. (B) Clamps to fix the vertebral spines. $(C)$ Mouse is artificially ventilated through a tracheal tube for single imaging. Clamps fix the vertebral column. Skin flaps form a reservoir for artificial cerebrospinal fluid (ACSF) in which the objective is immersed. (D) Exposed spinal cord after a laminectomy. 
H. Steffens et al.

2. Cut holes into the tendon layers above the back muscles to gain access to the lateral joint processes.

3. Fix the clamps at an angle that leaves enough space for the imaging objective (Fig. 1C).

For repetitive imaging it is best to mount the vertebral column before preparing the field of view.

Imaging lateral aspects of the spinal cord (e.g., the ventral roots or the dorsal root ganglia) requires clamps that can be tilted. After tilting the mouse by $\sim 80^{\circ}$, the lateral spinal cord and parts of the ventral roots can be exposed by moving the dorsal roots dorsally with a fine glass hook or a $0.3 \mathrm{~mm}$ metal hook. Care should be taken not to impact the spinal cord surface, the roots or the blood vessels. Dorsal root ganglia are accessible without shifting the dorsal roots.

Preparation for Imaging

4. Create a reservoir to hold the ACSF, to be able to properly use the water-immersion objective.

For single-imaging experiments:

i. Form walls for an ACSF reservoir by lifting the skin flaps with threads (Fig. 1A,C). If you image more laterally with a tilted mouse, form reservoir walls with skin flaps and small pieces of paper.

ii. Fill this pool with warm $2 \%$ agar in ACSF. Keep the region of interest free of agar by covering it with a piece of cotton soaked in ACSF.

iii. After the agar has hardened, cut a cone-shaped hole into the agar, making it large enough to remove the cotton and to insert the objective lens.

The surrounding agar will help to reduce undesirable movement at the region of interest.

For repetitive-imaging experiments:

i. Much less muscle and tendon are removed, so the remaining tissue will suffice as walls for the ACSF reservoir.

ii. Use only ACSF sterilized with filter tips for repeated-imaging experiments.

5. Fill the reservoir with ACSF.

Two-Photon Microscopy and Image Acquisition

6. Take a bright-field image from the surface of the spinal cord (Fig. 2A).

Use the pattern of blood vessels to image from compatible regions in different animals or to find the same location during repetitive imaging.

7. Set the laser to $920 \mathrm{~nm}$, a wavelength in which most fluorescent proteins (e.g., enhanced cyan fluorescent protein [eCFP], enhanced green fluorescent protein [eGFP], and enhanced yellow fluorescent protein [eYFP]) and sulforhodamine 101 (TexasRed) can be excited (Fig. 2B-D).

8. Separate eGFP and eYFP by using a 520-nm dichroic mirror and $500 \pm 12$-nm and $542 \pm 27$ nm emission filters (Fig. 2C).

9. Separate the fluorescence of Texas Red from an eGFP signal with a 560-nm long-pass filter and an HQ575 emission filter (Fig. 2B).

10. Use a 460/80BP emission filter for eCFP signals (Fig. 2D).

11. Record regions of the dorsal columns as uniformly spaced planes $(1-2 \mu \mathrm{m})$ of fields of view from $170 \times 170$ to $600 \times 600 \mu \mathrm{m}$ as $z$-stacks of images $(256 \times 256$ to $1024 \times 1024$ pixels in size). Voxel sizes should range from $0.24 \times 0.24 \times 1.5$ to $0.72 \times 0.72 \times 2.0 \mu \mathrm{m}$ for the $x$-, $y$-, and $z$ axis, respectively. The total acquisition time for a stack of 16-24 images will range from 1 to 2 $\min$.

See Troubleshooting. 

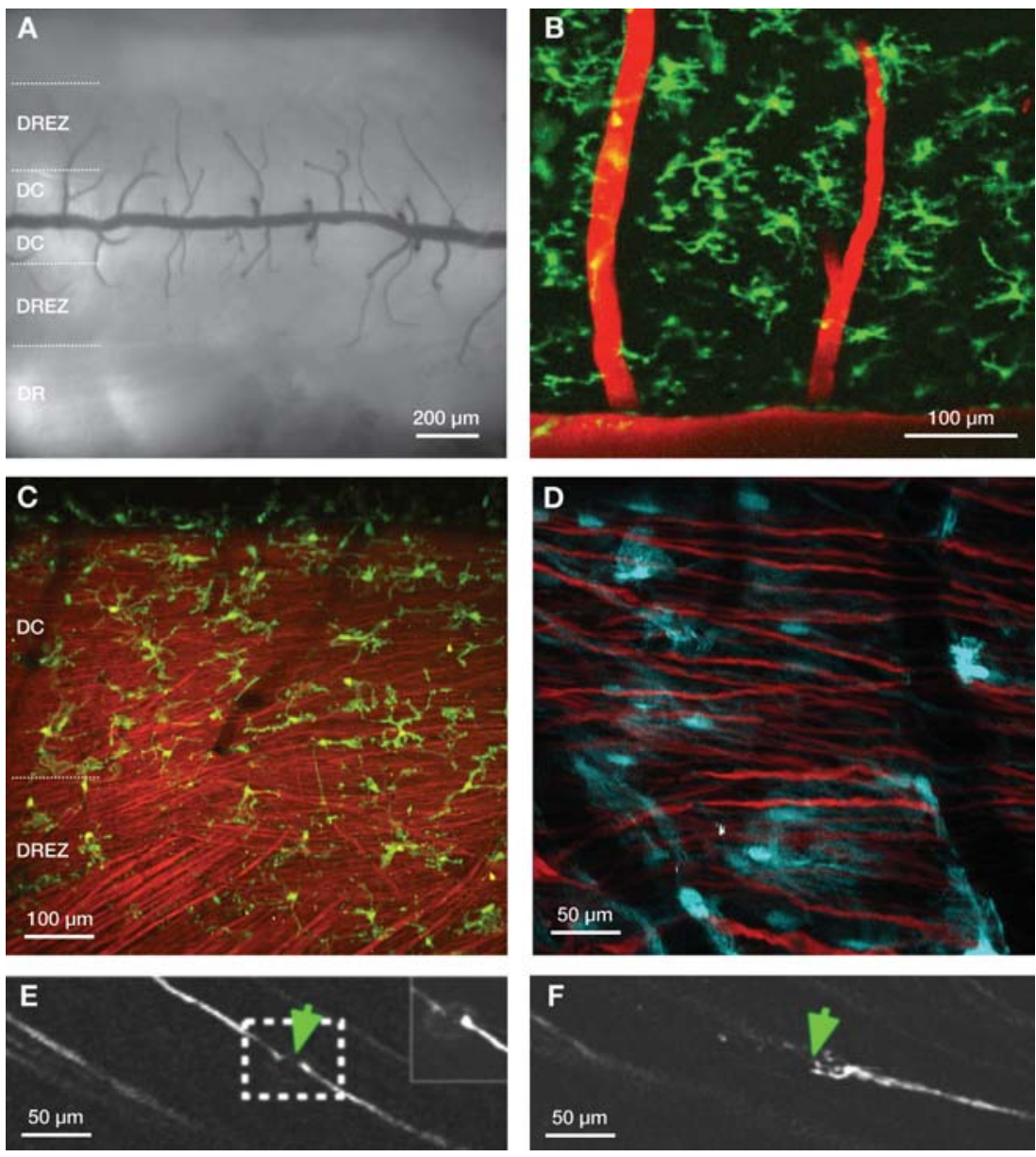

FIGURE 2. Images of the mouse spinal cord. (A) Bright-field overview of the spinal cord. Note the pattern of dark blood vessels. $(B)$ In vivo $2 \mathrm{pLSM}$ of green fluorescent microglia. The spinal capillaries are labeled with Texas Red-dextran by injection into the tail vein. $(C)$ Recording from a double-transgenic mouse $(\operatorname{TgH}(\mathrm{CX} 3 \mathrm{CR} 1-\mathrm{eGFP})) \times(\operatorname{TgN}(\mathrm{Thy} 1-\mathrm{eYFP}))$ with green fluorescent microglia and yellow fluorescent axons (shown in red). Note the oblique axons from the roots in contrast to the spinal axons running in parallel. $(D)$ Recording from a double-transgenic $(\operatorname{TgN}(\mathrm{GFAP}-\mathrm{eCFP})) \times(\mathrm{TgN}$ (Thy1-eYFP)) mouse. The thin lamellipodia of the cyan-fluorescent astrocytes are faint but clearly present. $(E, F)$ Repetitive imaging of single spinal axons in TgN(Thy1-eGFP) mice. (E) A single axon was dissected by a highpower laser pulse. Laser lesion was carried out on a square field of $7 \times 7 \mu \mathrm{m}$, laser power being set to $50 \%(1 \mathrm{~W})$, for one image (i.e., $\sim 0.5 \mathrm{sec}$ ). $(F)$ Three days later, the dissected axon shows some sprouting.

Problem (Step 11): Image resolution is not optimal.

Solution: Consider the following:

1. A very stable field of view is required to obtain high-resolution images. Thus, the holder should be placed as close as possible to the structure of interest (see the position of the clamps in Fig. 1). In most cases, this arrangement is sufficient for high-resolution imaging.

2. It is critical that the water-immersion objective pool built from the skin flaps of the wound is leakproof. If necessary, add a layer of $1.5 \%$ agarose to seal the pool against leaks. The agarose will also stabilize the spinal cord, which could improve image quality.

3. Too much motion could also be caused by a lack of muscle relaxant (Pancuronium). Therefore re-inject Pancuronium in time. 
H. Steffens et al.

\section{DISCUSSION}

Using the above protocol, we have obtained stable recordings continuously over several hours during a single imaging session. We have also been able to follow the progression of white matter scar formation by imaging repeatedly over a period of $>6$ mo. In addition, cell type-specific expression of eCFP, eGFP, and eYFP could be seen by simultaneously recording with four emission channels and subsequently performing spectral unmixing (Nadrigny et al. 2006; Neher et al. 2009).

A location that has optimal imaging conditions of white matter is found in the dorsal columns (DC) close to the dorsal central vein of the spinal cord. Here, we focused primarily on recordings of the lumbar segments receiving peripheral inputs from lower limbs, whereas others investigated spinal cord injuries at thoracic levels (Davalos et al. 2008; Dray et al. 2009). In our preparation, access to the DC can be achieved without a more invasive laminectomy. After careful removal of the dorsal parts of intervertebral discs and slight bending of the back, axons and glial cells of the white matter can be imaged repeatedly (Fig. 2E,F; Ylera et al. 2009).

More laterally, within the dorsal root entry zone (DREZ) region of the dorsal roots, ascending fibers and lamina I of the dorsal horn can be readily accessed (Fig. 2A,C). Johannssen and Helmchen (2010) achieved recording of stimulation-evoked $\mathrm{Ca}^{2+}$ transients from superficial neurons of this region. The pattern of the blood vessels and the consistency of the axons allow imaging of single cells and axons for several days and even months (Fig. 2).

\section{ACSF for $2 p L S M$}

$125 \mathrm{~mm} \mathrm{NaCl}$

$25 \mathrm{~mm} \mathrm{NaHCO}_{3}$

$2.5 \mathrm{~mm} \mathrm{KCl}$

$1.25 \mathrm{mM} \mathrm{KH}_{2} \mathrm{PO}_{4}$

$1 \mathrm{mM} \mathrm{MgCl}_{2}$

$2 \mathrm{mM} \mathrm{CaCl}_{2}$

$10 \mathrm{~mm}$ glucose

Bubble with carbogen ( 5 vol\% $\mathrm{CO}_{2} / 95 \% \mathrm{O}_{2}$ )

to generate and stabilize a $\mathrm{pH}$ of 7.3.

\section{REFERENCES}

Davalos D, Lee JK, Smith WB, Brinkman B, Ellisman MH, Zheng B, Akassoglou K. 2008. Stable in vivo imaging of densely populated glia, axons and blood vessels in the mouse spinal cord using two-photon microscopy. J Neurosci Meth 169: 1-7.

Dray C, Rougon G, Debarbieux F. 2009. Quantitative analysis by in vivo imaging of the dynamics of vascular and axonal networks in injured mouse spinal cord. Proc Natl Acad Sci 106: 9459-9464.

Johannssen HC, Helmchen F. 2010. In vivo $\mathrm{Ca}^{2+}$ imaging of dorsal horn neuronal populations in mouse spinal cord. J Physiol 588: 33973402.

Nadrigny F, Rivals I, Hirrlinger PG, Koulakoff A, Personnaz L, Vernet M, Allioux M, Chaumeil M, Ropert N, Giaume C, et al. 2006. Detecting fluorescent protein expression and co-localisation on single secretory vesicles with linear spectral unmixing. Eur Biophys $J$ 35: $533-547$.
Neher RA, Mitkovski M, Kirchhoff F, Neher E, Theis FJ, Zeug A. 2009. Blind source separation techniques for the decomposition of multiply labeled fluorescence images. Biophys J 96: 3791-3800.

Pologruto TA, Sabatini BL, Svoboda K. 2003. ScanImage: Flexible software for operating laser scanning microscopes. Biomed Eng Online 2: 13.

Steffens H, Nadrigny F, Kirchhoff F. 2012a. Preparation of the mouse spinal column for single imaging using two-photon laser scanning microscopy. Cold Spring Harb Protoc doi: 10.1101/pdb.prot072249.

Steffens H, Nadrigny F, Kirchhoff F. 2012b. Preparation of the mouse spinal column for repetitive imaging using two-photon laser scanning microscopy. Cold Spring Harb Protoc doi: 10.1101/pdb.prot072256.

Ylera B, Erturk A, Hellal F, Nadrigny F, Hurtado A, Tahirovic S, Oudega M, Kirchhoff F, Bradke F. 2009. Chronically CNS-injured adult sensory neurons gain regenerative competence upon a lesion of their peripheral axon. Curr Biol 19: 930-936. 


\section{In Vivo Two-Photon Imaging of Neurons and Glia in the Mouse Spinal Cord}

Heinz Steffens, Fabien Nadrigny and Frank Kirchhoff

Cold Spring Harb Protoc; doi: 10.1101/pdb.prot072264

\begin{tabular}{|c|c|}
\hline $\begin{array}{r}\text { Email Alerting } \\
\text { Service }\end{array}$ & Receive free email alerts when new articles cite this article - click here. \\
\hline $\begin{array}{l}\text { Subject } \\
\text { Categories }\end{array}$ & $\begin{array}{l}\text { Browse articles on similar topics from Cold Spring Harbor Protocols. } \\
\text { Fluorescence (517 articles) } \\
\text { Fluorescent Proteins ( } 259 \text { articles) } \\
\text { Imaging for Neuroscience ( } 342 \text { articles) } \\
\text { Imaging/Microscopy, general (579 articles) } \\
\text { In Vivo Imaging ( } 334 \text { articles) } \\
\text { Multi-Photon Microscopy (103 articles) } \\
\text { Neuroscience, general (357 articles) } \\
\text { Transgenic Mice (139 articles) }\end{array}$ \\
\hline
\end{tabular}

